Supporting Information

\title{
Lanthanide-doped $\mathrm{Bi}_{2} \mathrm{SiO}_{5} @ \mathrm{SiO}_{2}$ Core-Shell Upconverting Nanoparticles for Stable Ratiometric Optical Thermometry
}

\footnotetext{
Michele Back, ${ }^{1,2,+,{ }^{*}}$ Elisa Casagrande, ${ }^{1,+}$ Carlo A. Brondin, ${ }^{1}$ Emmanuele Ambrosi, ${ }^{1,3}$ Davide Cristofori, ${ }^{1,3}$ Jumpei Ueda, ${ }^{2}$ Setsuhisa Tanabe, ${ }^{2}$ Enrico Trave, ${ }^{1}$ Pietro Riello ${ }^{1}$

${ }^{1}$ Department of Molecular Sciences and Nanosystems, Università Ca’ Foscari Venezia, Via Torino 155, 30172 Mestre-Venezia, Italy

${ }^{2}$ Graduate School of Human and Environmental Studies, Kyoto University, Kyoto 606-8501, Japan 3 “Giovanni Stevanato" Centre for Electron Microscopy, Università Ca' Foscari Venezia, Via Torino 155, 30172 Mestre-Venezia, Italy

*Correspondence to: michele.back@unive.it
} 
Figure S1. FE-SEM images of Er-doped $\mathrm{Bi}_{2} \mathrm{O}_{3}$ NPs with different content of Er: (a) $0.5 \%$, (b) $1 \%$, (c) $2 \%$, (d) $4 \%$, (e) $6 \%$ and (d) $8 \%$.

Figure S2. XRPD pattern of the synthesized NPs.

Figure S3. Size distributions of the Er-doped $\mathrm{Bi}_{2} \mathrm{O}_{3} \mathrm{NPs}$ as a function of the Er content.

Figure S4. (a) FE-SEM and (b,c) HR-TEM images of the Er-doped $\mathrm{Bi}_{2} \mathrm{O}_{3} \mathrm{NPs}$ with $10 \%$ of Er.

Figure S5. Representative HR-TEM single particle images for different $\mathrm{SiO}_{2}$ shell thickness for the $\mathrm{Bi}_{2} \mathrm{O}_{3}$ NPs prepared with $\mathrm{NaOH}(\mathrm{a}-\mathrm{c})$ and urea (d-f).

Figure S6. (a) DSC curves, (b) XRPD patterns and (c,d,e) SEM images of the $\mathrm{Bi}_{2} \mathrm{O}_{3}: \mathrm{Er} @ \mathrm{SiO}_{2} \mathrm{NPs}$ with different silica shell thickness $(11 \pm 2 \mathrm{~nm}, 23 \pm 1 \mathrm{~nm}$ and $40 \pm 2 \mathrm{~nm})$ after the DSC analysis.

Figure S7. $(a, c)$ DSC curves and $(b, d)$ the XRPD patterns for the resulting crystalline phase of the undoped and 2 at.\% Er-doped $\mathrm{Bi}_{2} \mathrm{O}_{3}$ NPs.

Figure S8. HR-TEM image and EDS spectra recorded for the $\mathrm{Bi}_{2} \mathrm{SiO}_{5}: \mathrm{Er} @ \mathrm{SiO}_{2}$ sample treated at $700{ }^{\circ} \mathrm{C}$ : (1) $\mathrm{SiO}_{2}$ shell, (2) $\mathrm{Bi}_{2} \mathrm{SiO}_{5}:$ Er layer and (3) the center of the hollow particle.

Figure S9. Logarithmic values of integrated PL intensity versus pumping power density of the ${ }^{2} \mathrm{H}_{11 / 2} \rightarrow{ }^{4} \mathrm{I}_{15 / 2},{ }^{4} \mathrm{~S}_{3 / 2} \rightarrow{ }^{4} \mathrm{I}_{15 / 2}$ and ${ }^{4} \mathrm{~F}_{9 / 2} \rightarrow{ }^{4} \mathrm{I}_{15 / 2}$ transitions. 
(a)

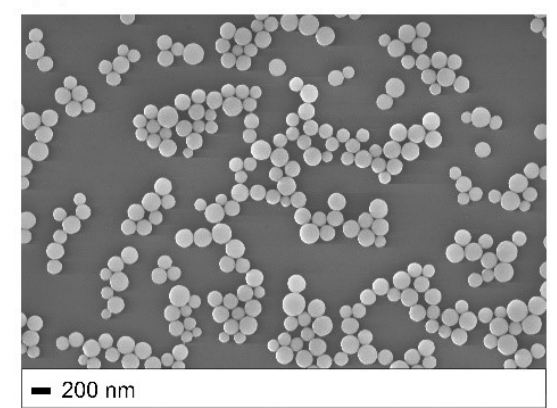

(d)

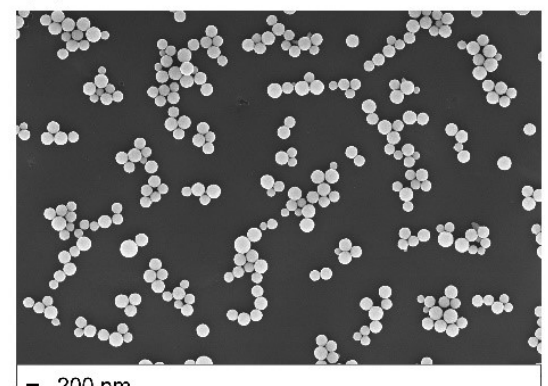

(b)

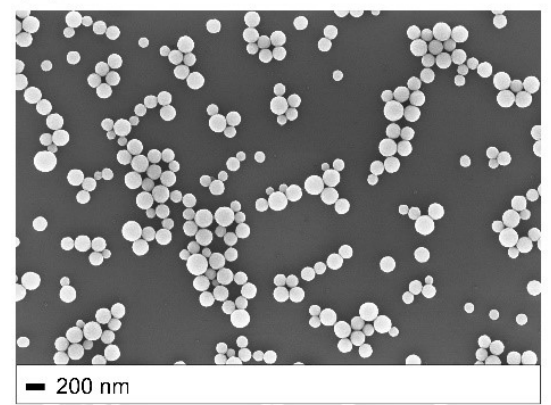

(e)

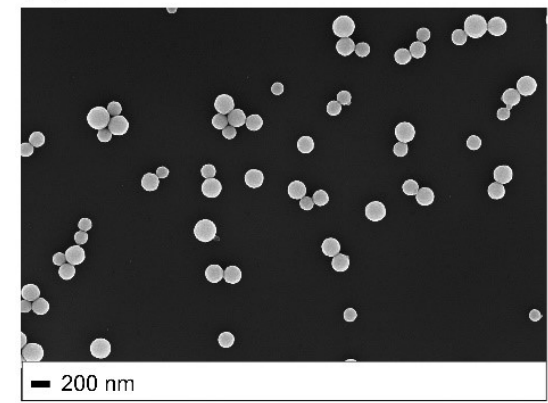

(c) Er 2
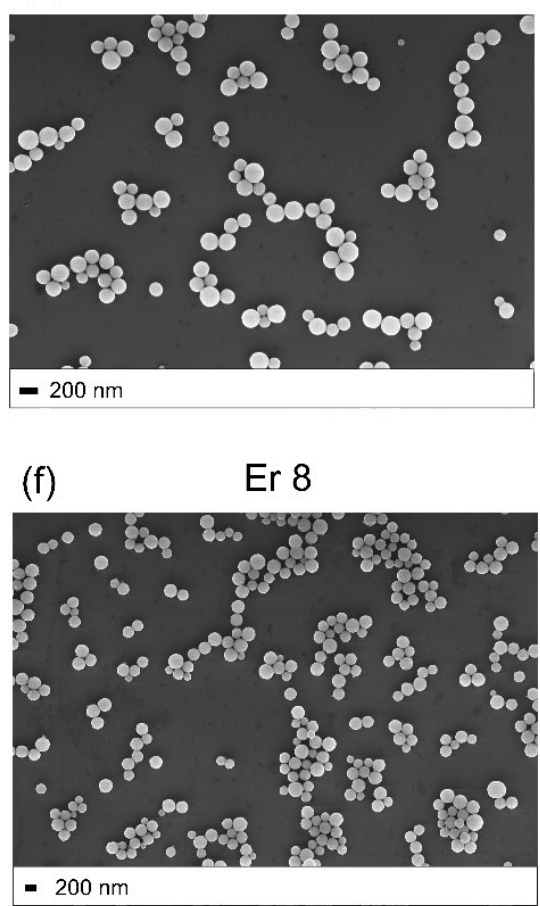

Figure S1. FE-SEM images of Er-doped $\mathrm{Bi}_{2} \mathrm{O}_{3}$ NPs with different content of Er: (a) $0.5 \%$, (b) $1 \%$, (c) $2 \%$, (d) $4 \%$, (e) $6 \%$ and (d) $8 \%$.

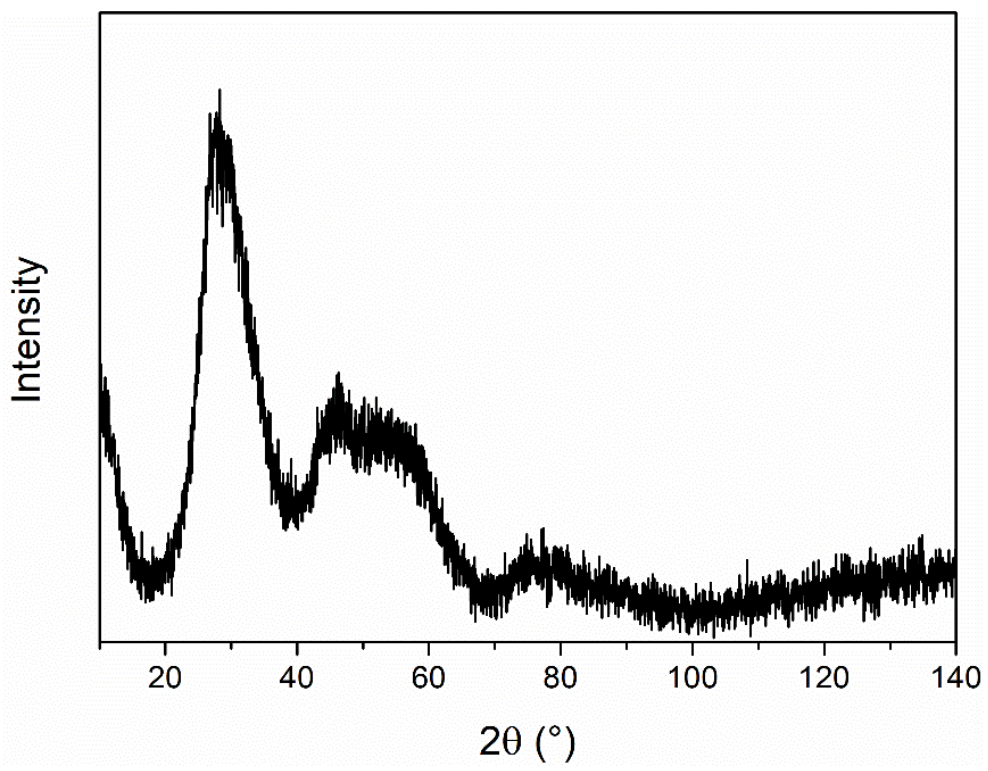

Figure S2. XRPD pattern of the synthesized NPs. 


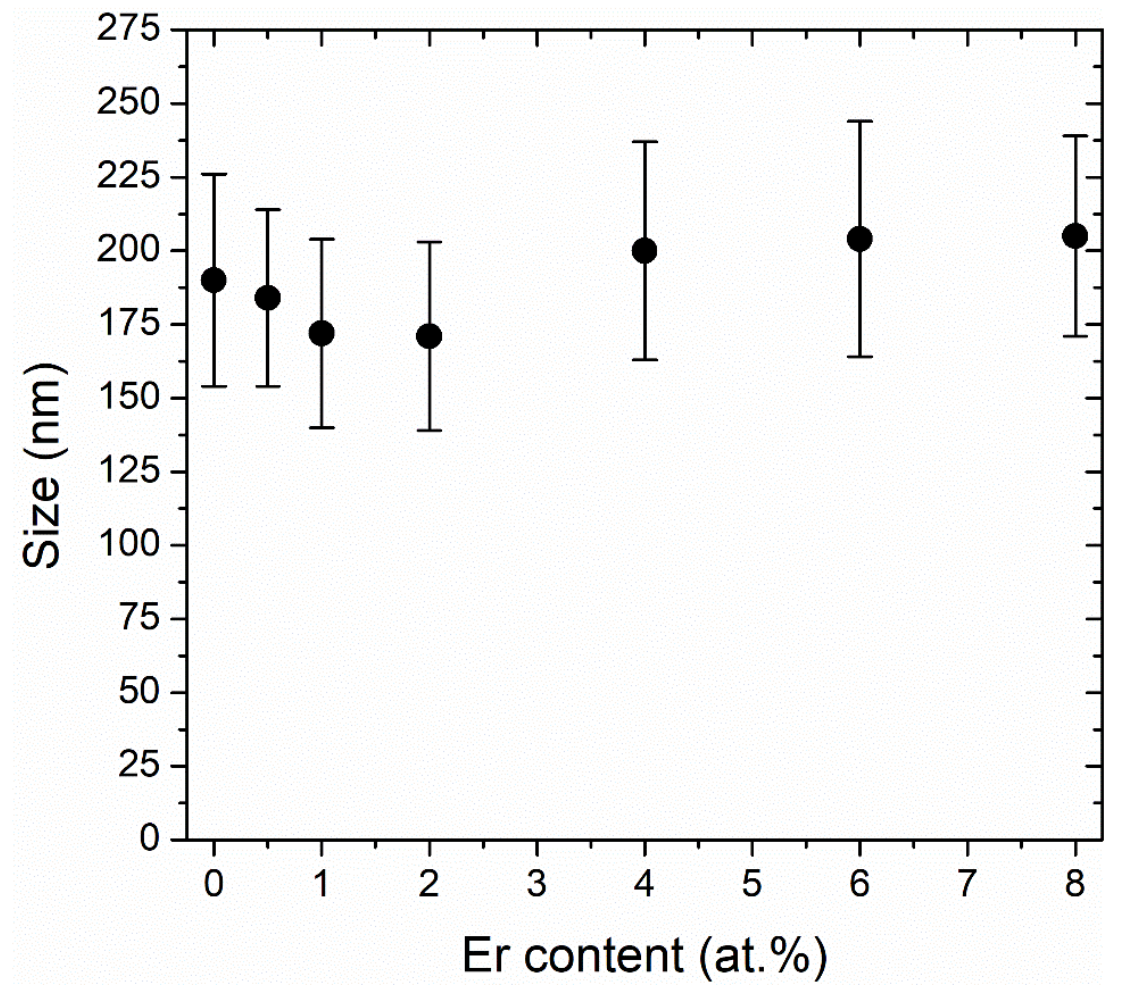

Figure S3. Size distributions of the Er-doped $\mathrm{Bi}_{2} \mathrm{O}_{3} \mathrm{NPs}$ as a function of the Er content.

(a)

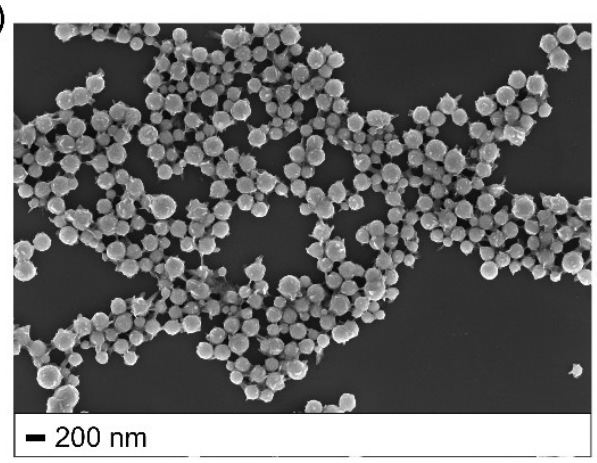

(d)

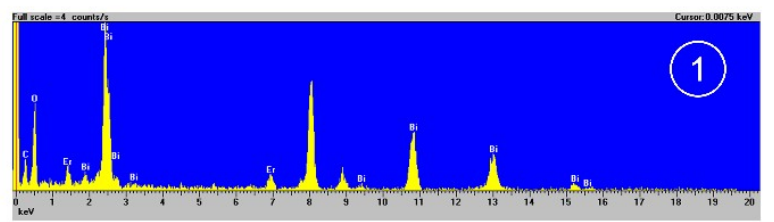

(b)

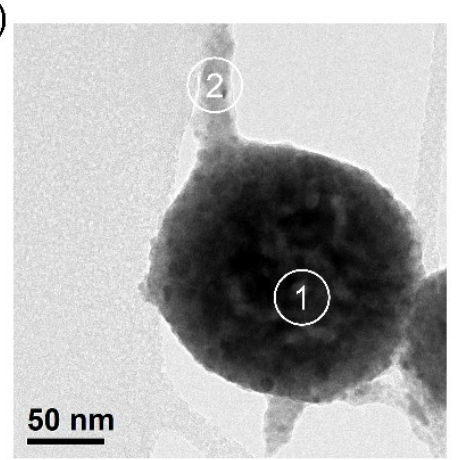

(c)

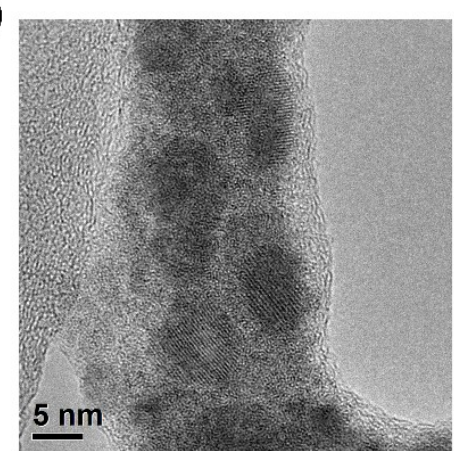

(e)

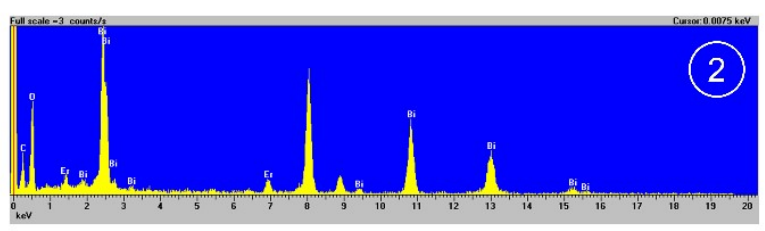

Figure S4. (a) FE-SEM, (b,c) HR-TEM images and (d,e) EDS analysis of Er-doped $\mathrm{Bi}_{2} \mathrm{O}_{3} \mathrm{NPs}_{\text {sith }}$ $10 \%$ of Er. 


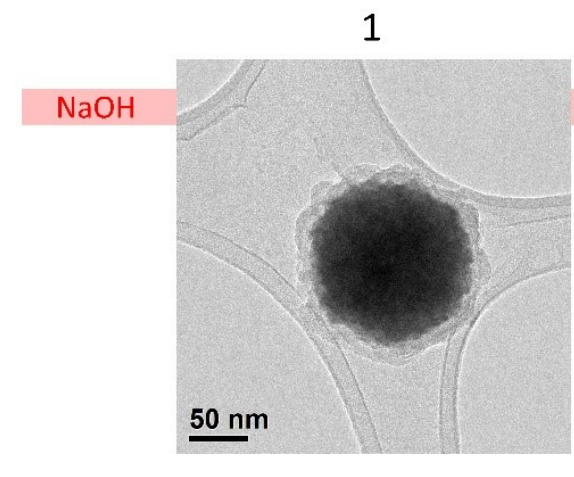

1

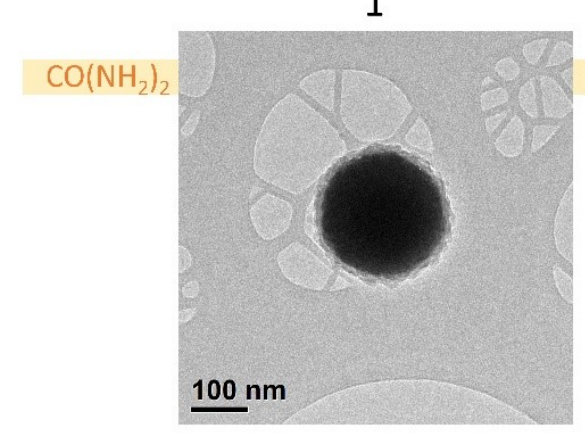

2

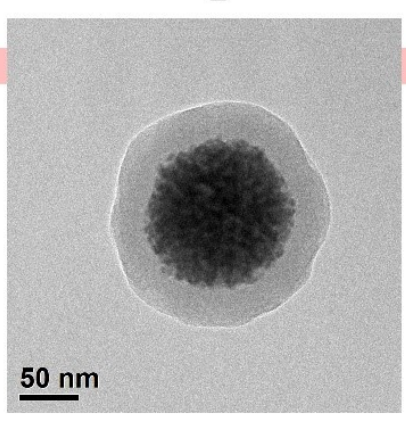

2

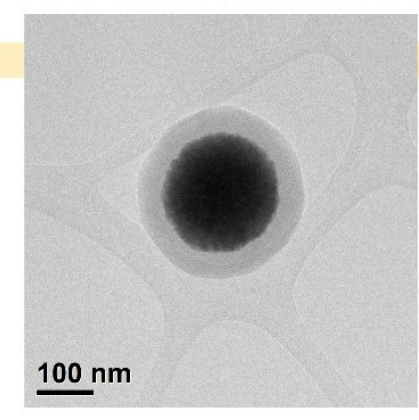

8

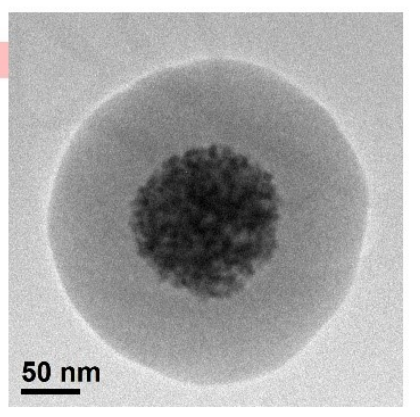

8

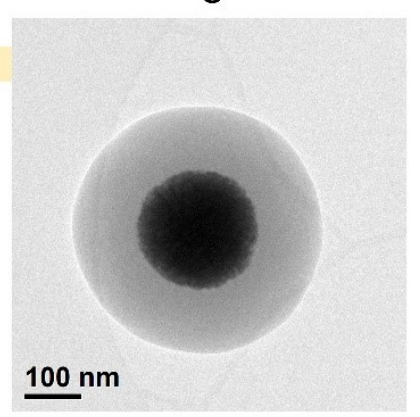

Figure S5. Representative HR-TEM single particle images for different $\mathrm{SiO}_{2}$ shell thickness for the $\mathrm{Bi}_{2} \mathrm{O}_{3}$ NPs prepared with NaOH (a-c) and urea (d-f). The numbers represent the TEOS ( $\left.\mu \mathrm{L}\right): \mathrm{Bi}_{2} \mathrm{O}_{3}(\mathrm{mg})$ ratio $(1,2$, and 8$)$. 
(a)

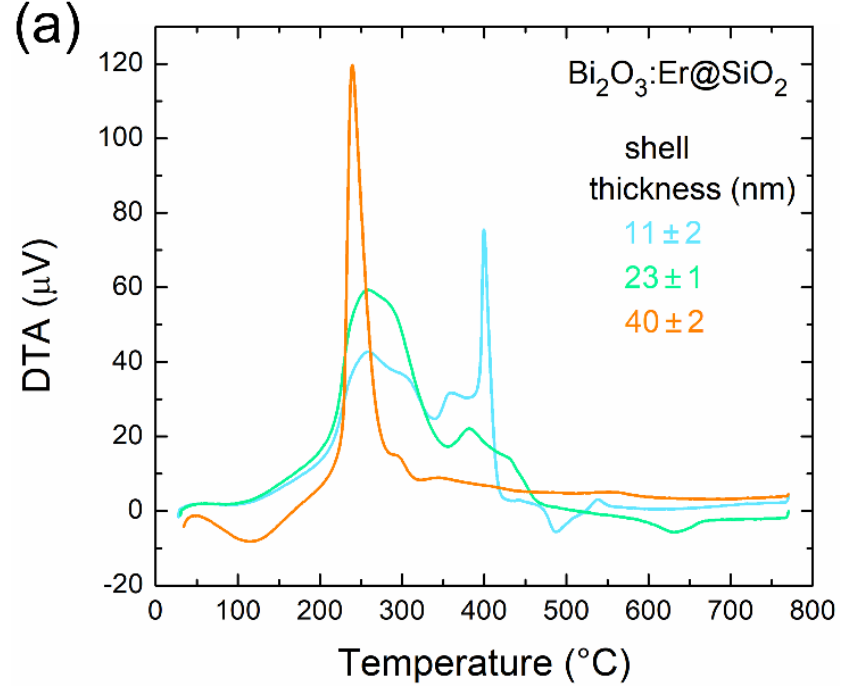

(b)

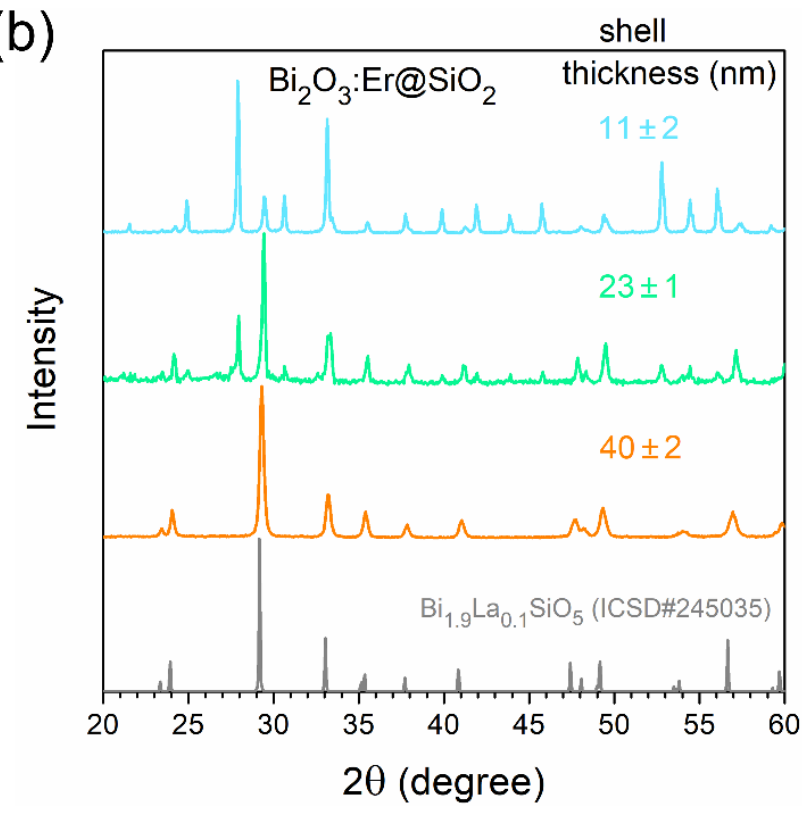

(c)

(d)
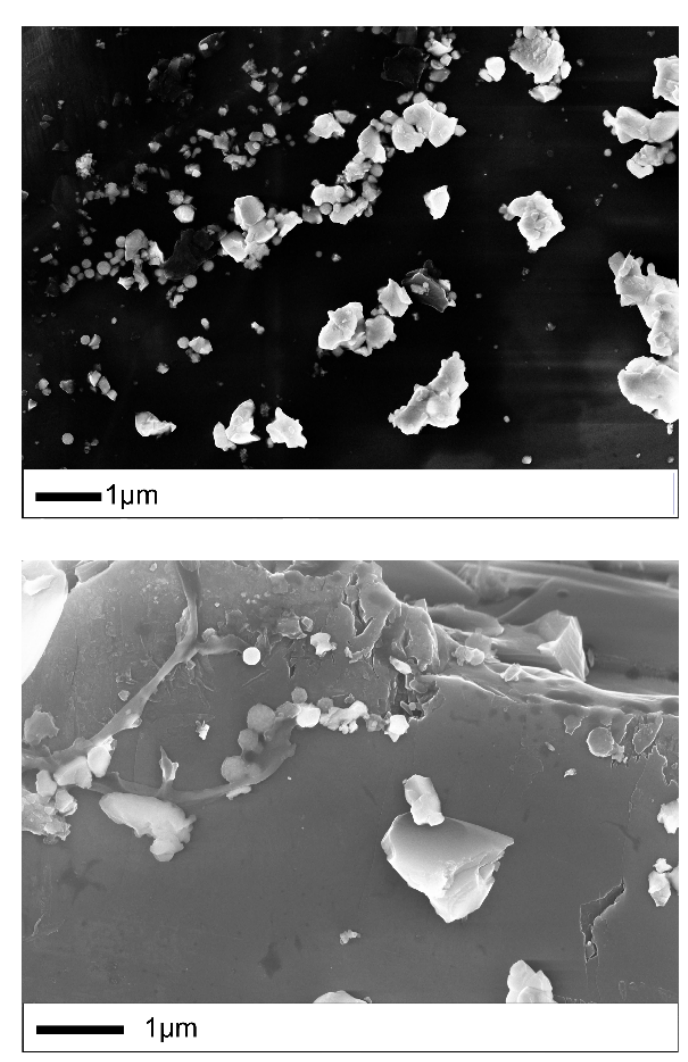

(e)

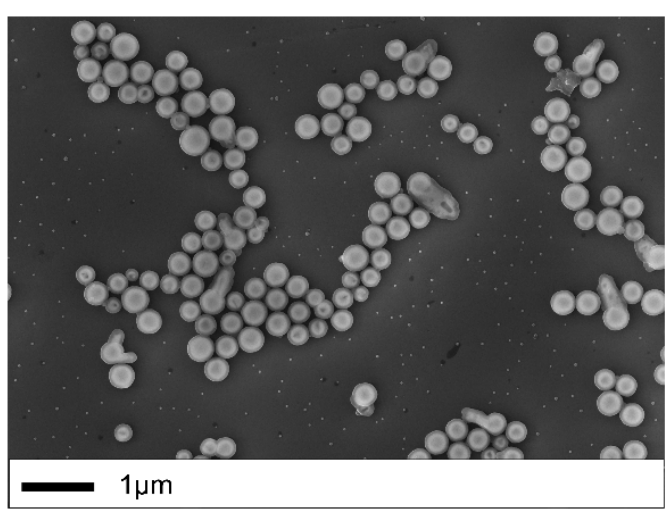

Figure S6. (a) DSC curves, (b) XRPD patterns and (c,d,e) SEM images of the $\mathrm{Bi}_{2} \mathrm{O}_{3}: \mathrm{Er} @ \mathrm{SiO}_{2} \mathrm{NPs}$ with different silica shell thickness $(11 \pm 2 \mathrm{~nm}, 23 \pm 1 \mathrm{~nm}$ and $40 \pm 2 \mathrm{~nm})$ after the DSC analysis. 

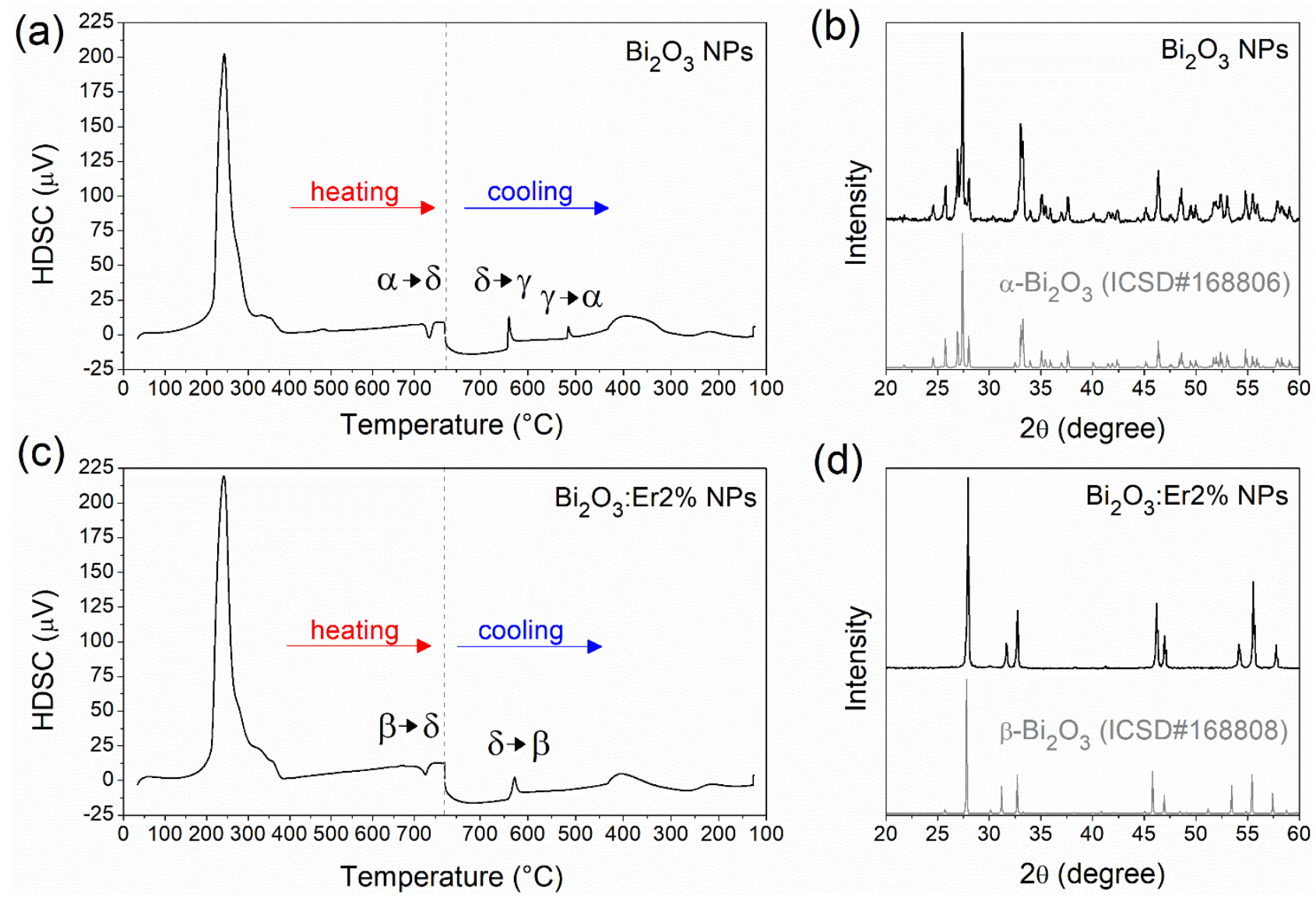

Figure S7. (a,c) DSC curves and $(b, d)$ the XRPD patterns for the resulting crystalline phase of the undoped and 2 at.\% Er-doped $\mathrm{Bi}_{2} \mathrm{O}_{3}$ NPs.
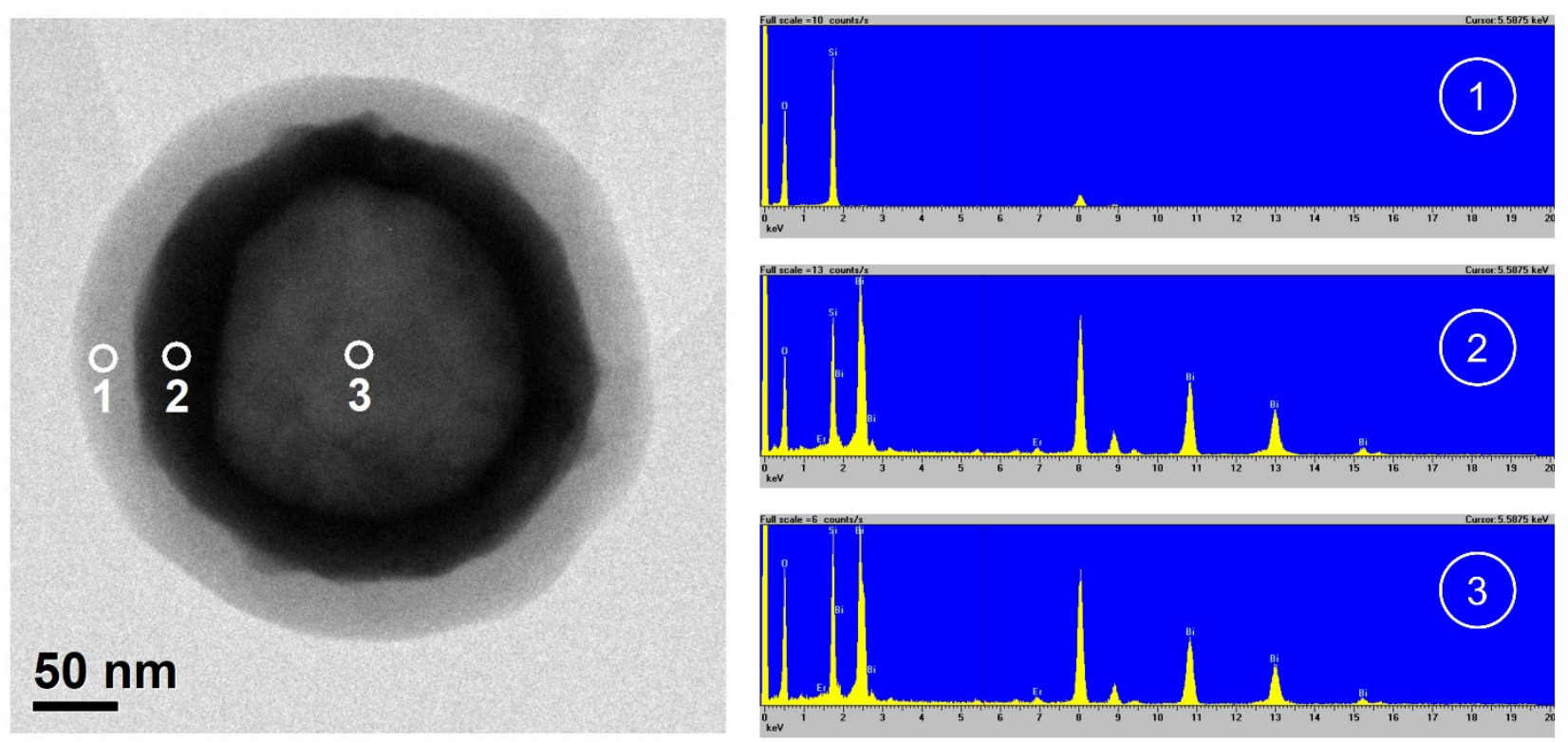

Figure S8. HR-TEM image and EDS spectra recorded for the $\mathrm{Bi}_{2} \mathrm{SiO}_{5}: \mathrm{Er} @ \mathrm{SiO}_{2}$ sample treated at $700{ }^{\circ} \mathrm{C}$ : (1) $\mathrm{SiO}_{2}$ shell, (2) $\mathrm{Bi}_{2} \mathrm{SiO}_{5}:$ Er layer and (3) the center of the hollow particle. 


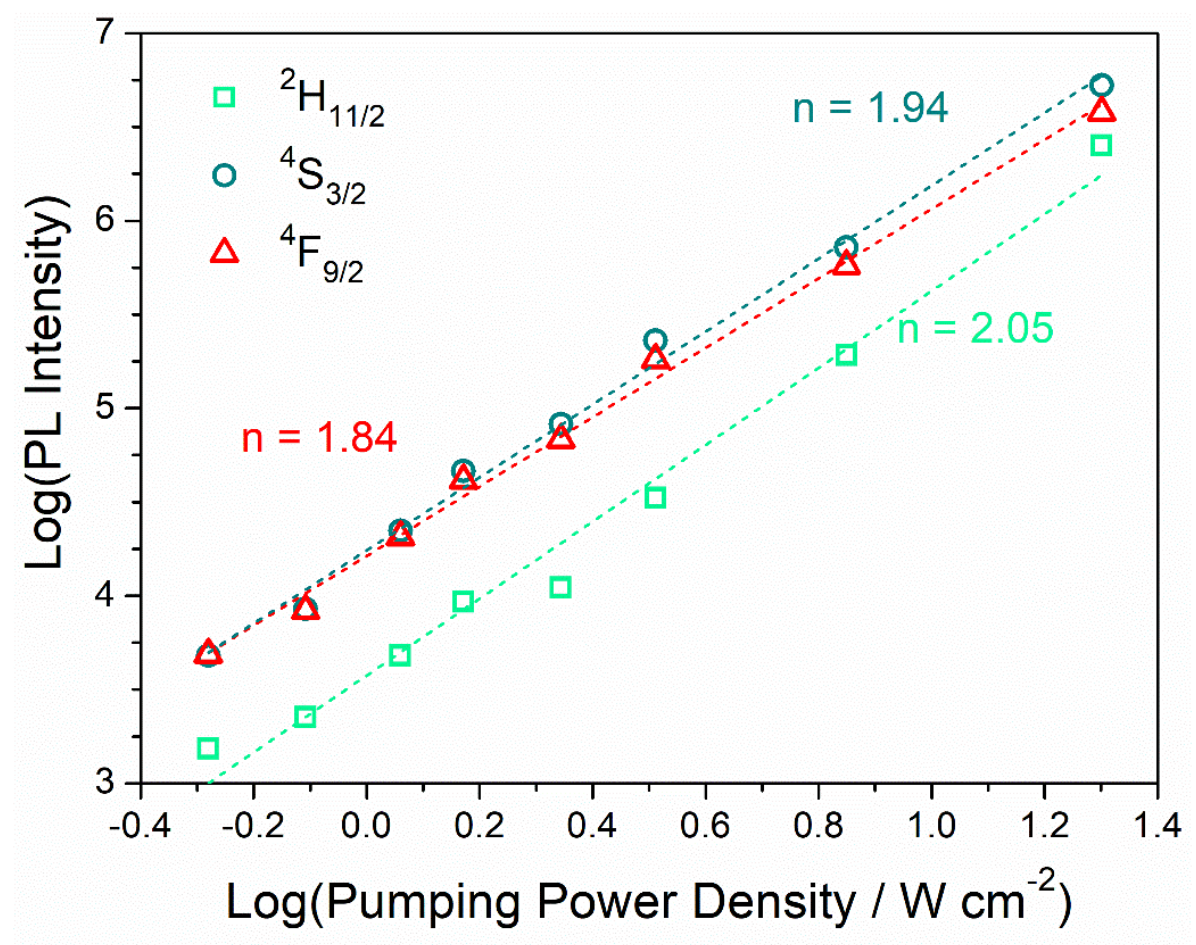

Figure S9. Logarithmic values of integrated PL intensity versus pumping power density of the ${ }^{2} \mathrm{H}_{11 / 2} \rightarrow{ }^{4} \mathrm{I}_{15 / 2},{ }^{4} \mathrm{~S}_{3 / 2} \rightarrow{ }^{4} \mathrm{I}_{15 / 2}$ and ${ }^{4} \mathrm{~F}_{9 / 2} \rightarrow{ }^{4} \mathrm{I}_{15 / 2}$ transitions. 